\title{
Corrigendum: Discovery of Novel Doxorubicin Metabolites in MCF7 Doxorubicin-Resistant Cells
}

\author{
Xu Wang ${ }^{\dagger}$, Renjie Huit ${ }^{\dagger}$ Yun Chen, Wentao Wang, Yujiao Chen, Xiaohai Gong and Jian Jin* \\ School of Pharmaceutical Sciences, Jiangnan University, Wuxi, China
}

Keywords: drug resistant, doxorubicin, intracellular drug metabolism, LC-MS/MS, breast cancer

A corrigendum on

Discovery of Novel Doxorubicin Metabolites in MCF7 Doxorubicin-Resistant Cells by Wang, X., Hui, R., Chen, Y., Wang, W., Chen, Y., Gong, X., and Jin, J. (2019). Front. Pharmacol. 10: 1434. doi:10.3389/fphar.2019.01434

Edited and reviewed by: Salvatore Salomone, University of Catania, Italy

*Correspondence: Jian Jin

jianjin@jiangnan.edu.cn

${ }^{+}$These authors have contributed equally to this work

Specialty section: This article was submitted to Experimental Pharmacology and Drug Discovery, a section of the journal

Frontiers in Pharmacology

Received: 07 September 2020

Accepted: 15 October 2020

Published: 26 November 2020

Citation:

Wang X, Hui R, Chen Y, Wang W, Chen

$Y$, Gong $X$ and Jin J (2020)

Corrigendum: Discovery of Novel

Doxorubicin Metabolites in

MCF7 Doxorubicin-Resistant Cells.

Front. Pharmacol. 11:603491.

doi: 10.3389/fphar.2020.603491
In the original article, there were several errors. A correction has been made to:

Section Materials and Methods, sub-section Cell Culture, paragraph 1:

"Human breast cancer cell MCF7 was purchased from ATCC and the multidrug resistance MCF7/DOX cell line was developed based on MCF7 (Yan et al., 2006). Starting from 1/10 of the IC50, the DOX concentration in the medium was gradually increased after the cells were stably grown. After that, MCF7/ DOX resistant cell lines with stable drug resistance index of more than 200 times were obtained. Both cell lines were cultured in Dulbecco's modified Eagle's medium (DMEM; Invitrogen Corp., CA, United States) supplemented with $10 \%$ fetal bovine and $2 \mathrm{U} / \mathrm{ml}$ insulin. Cells were grown in incubators at $37^{\circ} \mathrm{C}$ and $5 \% \mathrm{CO}_{2}$."

Section Materials and Methods, sub-section LC-MS Analysis, paragraph 1:

"Chromatographic separation was performed on ACQUITY UPLC BEH C18 Column $(1.7 \mu \mathrm{m}$, $2.1 \mathrm{~mm} \times 50 \mathrm{~mm}$ ) to separate different metabolite components. $0.1 \%$ formic acid aqueous solution (phase A)/ Methanol (phase B) was selected as mobile phases. The proportions of mobile phase A:B was initially 90:10 and switched to $5 \%$ phase A from 0.1 to $9 \mathrm{~min}$, then switch back to $10 \%$ of phase $\mathrm{B}$ from 11 to $11.5 \mathrm{~min}$ and keep $10 \%$ phase B until $15 \mathrm{~min}$. The mobile phase was delivered at a rate of $0.2 \mathrm{ml} /$ min. The column temperature was maintained at $20^{\circ} \mathrm{C}$. The injection volume is $5 \mu \mathrm{l}(\mathrm{MCF} 7 / \mathrm{DOX})$ and $2 \mu \mathrm{l}(\mathrm{MCF} 7 / \mathrm{WT})$. Ultraviolet detection was set at the wavelength $480 \mathrm{~nm}$, which correspond to the specific wavelength of anthracycline structure in Doxorubicin and its metabolites (Cummings et al., 1991). Multi-stage mass spectrometry was performed on LTQ Orbitrap XL in positive ion mode with HESI. Source Voltage was set at 4,300 V, and APCI Vaporizer temperature was $100^{\circ} \mathrm{C}$. The capillary voltage was $44 \mathrm{~V}$ and the temperature was $300^{\circ} \mathrm{C}$. Normalized Collision Energy was $35 \mathrm{eV}$.”

Section Discussion, paragraph 3:

"We have developed an intracellular trace metabolites extraction and LC-MS analysis method to identify doxorubicin metabolites in drug-resistant and sensitive cells. After high-resolution multistage mass spectrometry was used to detect doxorubicin structural analogs, we found that the fragmentation processes of these metabolites have commonalities and the structures inferred by mass 
fragmentation pattern are similar. We suspect that doxorubicin is modified in the drug-resistant cell by a series of related metabolic enzymes. Although only three of these metabolites are mentioned, there are still many suspected metabolites with $\mathrm{m} / \mathrm{z} 395 \rightarrow 377$ characteristic mass fragmentation pattern that have not yet been analyzed. After drug treatment for different time $(4-36 \mathrm{~h})$, intracellular doxorubicin and its metabolites gradually accumulate over time, with no other differences."
The authors apologize for these errors and state that this does not change the scientific conclusions of the article in any way. The original article has been updated.

Copyright $\odot 2020$ Wang, Hui, Chen, Wang, Chen, Gong and Jin. This is an open-access article distributed under the terms of the Creative Commons Attribution License (CC BY). The use, distribution or reproduction in other forums is permitted, provided the original author(s) and the copyright owner(s) are credited and that the original publication in this journal is cited, in accordance with accepted academic practice. No use, distribution or reproduction is permitted which does not comply with these terms. 